\title{
\$ Underground and Independent Comics, Comix, and Graphic Novels
}

Composite Score:

$\star \star \star \star 1 / 4$
Reviewed by: Mary Claire Vandenburg

Queen's University

99 University Avenue

Kingston, Ontario K7L 3N6

Canada

$<$ mcv@queensu.ca $>$

\begin{abstract}
Comic Studies is an academic field focusing on the contribution of comic books and graphic novels as pop culture texts which increase our understanding of our common culture and analyse the reader's response provoked by the combined text and image. Comic studies theorists situate comics as complex texts requiring multimodal literacy worthy of study and critical interpretation. It is increasingly common to see humanities departments offer individual courses devoted to the study of comics and graphic novels with some academic institutions offering Comic Studies degrees. For the academic librarian seeking to prepare researchers to join this scholarly discourse or expand their existing collection, Alexander Street Press offers Underground and Independent Comics, Comix, and Graphic Novels. The review aims to assist librarians in deciding if the database will ably equip them to do so.
\end{abstract}

\section{Pricing Options}

Underground and Independent Comics, Comix, and Graphic Novels (UIC) is available to libraries worldwide with flexible purchase options. Institutions have the choice to purchase rights in perpetuity or acquire an annual subscription which expires without rights at closing. Pricing for the ownership or lease model varies depending on type of institution (academic, public library, etc.) as well as size of the acquisition budget. Ownership will run from $\$ 12,500$ to $\$ 50,000$ plus an annual access fee and subscription from $\$ 800$ to $\$ 4,300$ annually.

Both options offer unlimited access and MARC records which are included at no additional cost. To weigh this product's value in relation to its price tag; the considerable cost to the library in collection development hours, acquisitions handling, technical services, and circulation staffing of an equivalent paper collection ought to be considered. While the collection is expensive it provides excellent value. Consortia discounting is available and institutions should contact Alexander Street Press for pricing information and trial access.

\section{Product Description}

UIC provides a scholarly online collection for researchers and students of alternative, adult comic books and graphic novels with a focus on the North American market. UIC will be most useful where the library has not invested in acquiring an extensive paper collection during the years when the academic study of these materials was not broadly accepted. There are no comparable products to the current release as it offers digitized full colour (where available) versions of
248 comic series, 1,408 comic books totalling 88,297 pages, with an aim to reach more than 100,000 pages. The editor of UIC describes the collection as a scholarly, academic assemblage of sequential art, not a loose collection of "capes and tights" stories. ${ }^{1}$

\section{Critical Evaluation CONTENT}

In addition to gathering this primary source material (the comics themselves) for current and future scholars, UIC also contains journal articles from Gary Groth's The Comics Journal archive from 1977 to 2009 , featuring the interviews, reviews, and criticism that record the evolution of this art form from its status as underground, special interest reading to career building examination by the academy. This secondary source material will prove invaluable to researchers seeking biographical information and opinion from the most celebrated and studied names in comic arts: Robert Crumb, Art Spiegelman \& Kevin Huizenga, Alison Bechdel, Will Eisner, and Seth $(<$ http://comx.alexanderstreet.com/View/1466366>).

While Alexander Street has achieved an enormous feat in bringing together cover to cover primary and secondary source material, monograph, and documentary history with UIC, the academic librarian looking to provide the campus with a first rate current research collection will still have to collect journals such as the International Journal of Comic Art (currently only available in paper), individual titles of comics from Fantagraphics, graphic novels from Drawn \& Quarterly and Tokyopop, or Del Rey Manga for the international manga genre. While not completely comprehensive, the effort to secure licensing for this vast collection of publishers and artists must been herculean, and for what it sets out to capture and make available, which is a great deal, the UIC database is wonderfully successful.

In addition to the comics primary source material, and Comics Journal, the database provides the full digitized copy of The Seduction of the Innocent by psychiatrist Dr. Frederick Wertham. First published in 1953 in the Ladies' Home Journal as an article titled "What parent's don't know about comic books," Wertham fully expanded into a quasi-scientific monograph which warned that comics contribute to juvenile delinquency by undermining legal, moral, and religious norms. Wertham levelled these accusations equally against horror or "crime comics," which valorise violence and the "capes and tights" superheroes like Superman, Batman, and Wonder Woman. ${ }^{2}$

UIC also provides documentary evidence of the Hearings Before the Subcommittee to Investigate Juvenile Delinquency of the Committee on the Judiciary United States Senate from 1954. Dr. Wertham testi- 
FIGURE 1 Advanced search

fied at the hearings as did comic book creator Walt Kelly (Pogo) and various distributors. The writer appreciates how much time has changed political sentiment when she reads in the hearings "Authorities agree that the majority of comic books are as harmless as soda pop." Despite this agreement to the inoffensive nature of most comic materials, as a result of these hearings and self-censorship on the part of the industry begun six years earlier in an effort to pre-empt greater restriction, readership of all comics plummeted in the mid-1950s. The self-policing of the industry lead to systematization by the Comics Magazine Association of America in the Comics Code which enumerated the prohibited themes and treatment of topics in comics. The Code itself is included here with annotations describing the specific comic titles targeted by the bans. As an unintended consequence of these attempts to control the social phenomenon of comics, the underground comix movement was spawned.

This database will appeal to researchers in English literature and language, Sociology, History, Cultural Studies, and Art. A word of warning for the public librarian reader, it is no coincidence that Alexander Street Press describes this resource as "for researchers and students of adult comic books and graphic novels." This collection is targeted at the academic market. One of the many Browse options is for Genre, the first option being Adult which currently has the most genre content, with Humor a close second. The depictions of sex, violence, drug use, and other adult content makes clear why a Comics Code (first introduced in 1954 and only recently abandoned) was developed and why access to these materials remain controversial. ${ }^{3}$

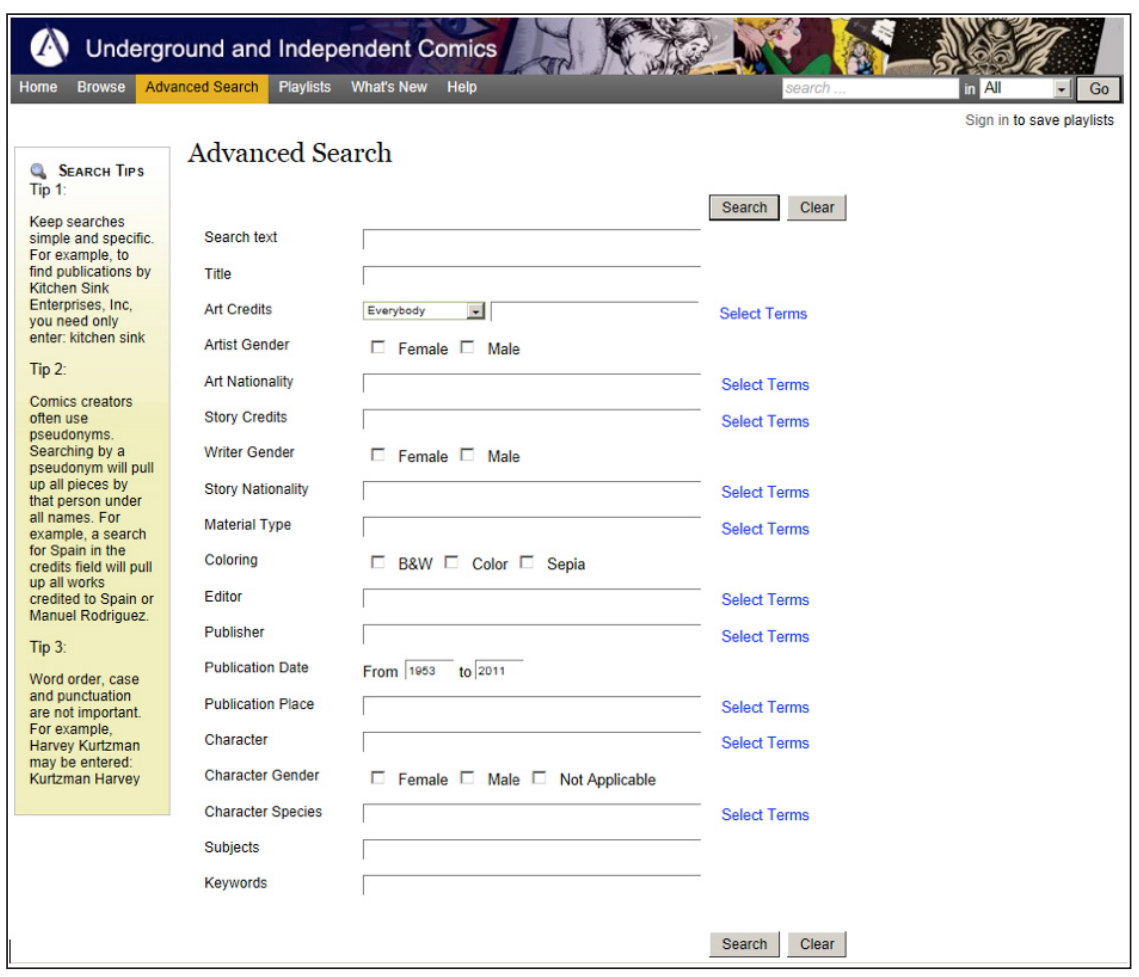

A small quibble with the results sorting feature: I would like the option to sort large results list not by the two options provided, relevancy and tile alphabetical, but by publication date chronological and reverse chronological. More importantly, I also found it difficult to separate out a search for graphic novel to exclude comic strip or feature as the Material Type limiter does not include graphic novel. Also, if ever there was an electronic resource where the next page function calls for page-turning software that mimics real, book in-hand reading, this would be it. This feature would also increase the desirability of using UIC on a tablet. However, the help feature does provide this

\section{INTERFACE}

Alexander Street presents an intuitive interface with flexible, Boolean-supported search functionality allowing for pseudonym searches and variations of word order, case, and punctuation. The advanced search screen allows the comics enthusiast a granularity of search uncommon in most databases. For example, one could search the Art Credits field for "Everybody" or specify artists on individual elements of the illustrations such as the inker or letterer. A pop-up box of names to select from is presented in list form to add to your search.

As you would expect from Alexander Street given the subject matter, the interface is brilliantly colourful with crisp thumbnail images embedded in the search results.

FIGURE 2 Select search term

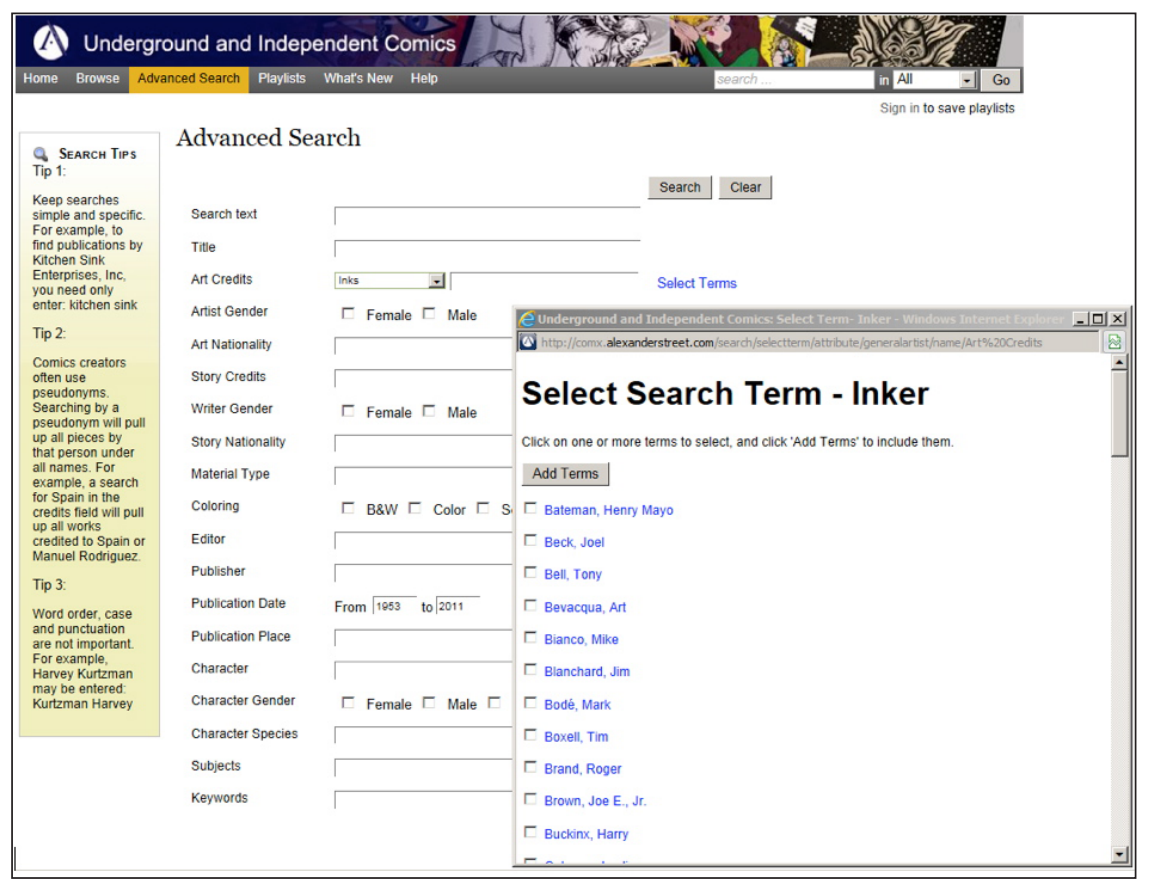



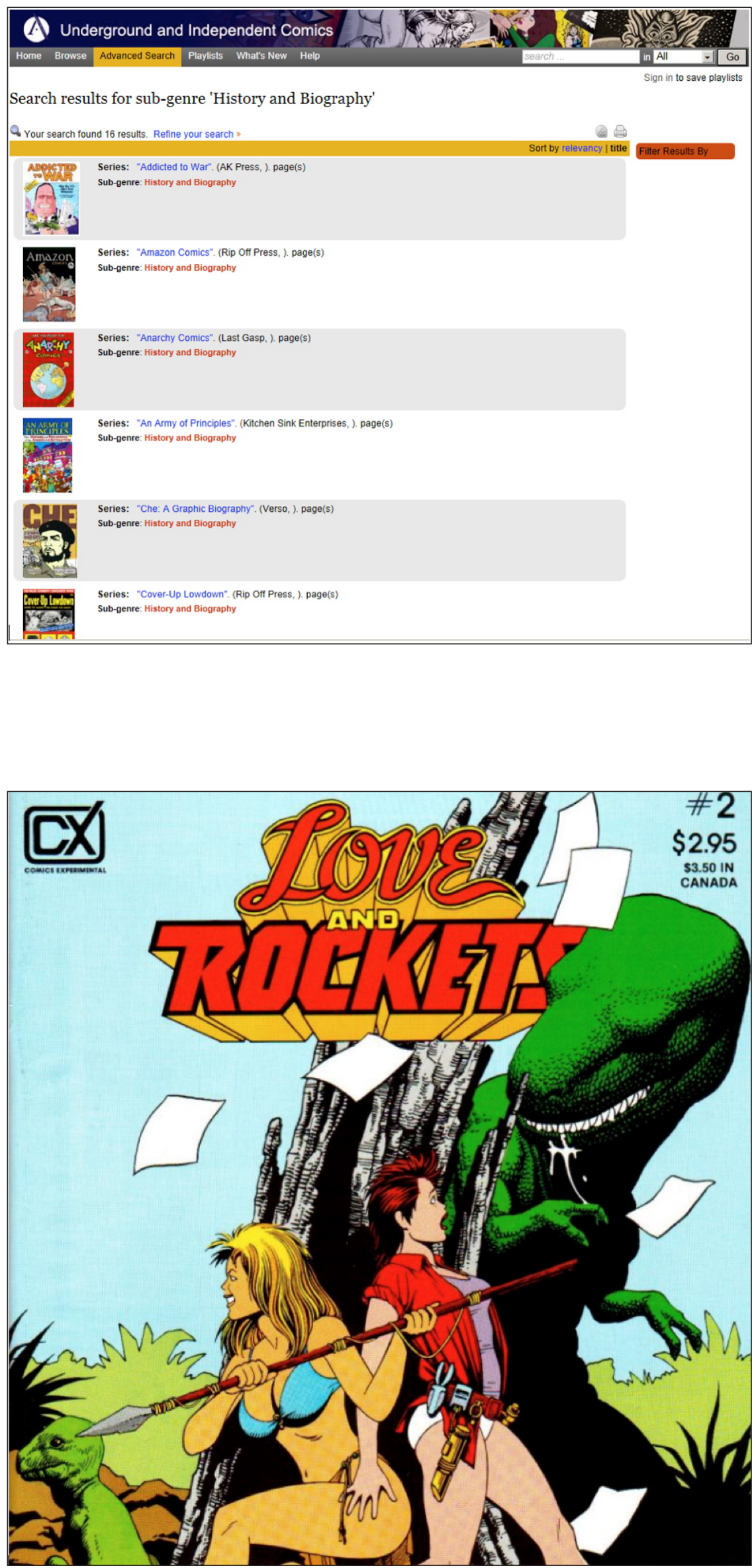

FIGURE 3 Sub-genre search results

tip: When viewing on a laptop or adjustable monitor, the zoom and horizontal rotation features can be used to more closely replicate the experience of reading a printed comic book. This appears to be the only consideration given to the experience of reading comics and graphic novels online. All use of the database content is confined to the UIC image viewer; there are no PDF downloads, and right clicking is disabled making cutting and pasting of image and text impossible nor is UIC downloadable to an e-book reader.

\section{TOOLS AND ENHANCEMENTS}

Alexander Street has clearly done its work in getting to know how academics might use this resource in enabling users to create playlists containing whole works, segments, and other enhancements such as permanent links to any URL and facilitated RSS feeds. Playlists can be annotated, edited, copied, and shared, and all playlists contain their own unique static URL. UIC provides a permanent URL for each item in the database which can be used to directly embed links into teaching resources, Learning Management Systems, Web pages and e-mails. The static URL is clearly found and captured by clicking on the static URL icon (a small globe) next to each work in the upper right area of the screen.

Playlists can be created to list personal favorites, to assign class viewing, or as a teaching resource for in-class use. Users will find that the playlist section comes prepopulated by Greg Urquhart, comics editor at Alexander Street, demonstrating what can be accomplished with expert use of all the features provided. For instance, Urquhart spotlights the Ghost World story arc, underground comix by female writers and artists, and the first Love \& Rockets storyline to feature Maggie the Mechanic, introducing the characters and themes Jaime Hernandez develops in his Locas stories. Becoming an adept user of UIC is enabled by a fully explained Help section where an investment of a short amount of time will pay dividends.

\section{Authentication and Contract Provisions}

The system requirements are optimized to operate with Microsoft Internet Explorer 7.0 or higher and Firefox 3.0 or higher. Authentication is provided to authorized users through IP address, and to re-

FIGURE 4 Love and Rockets, no. 2, by Gilbert Hernandez and Jaime Hernandez (Seattle, WA: Fantagraphics Books, 1983 


\section{Underground and Independent Comics, Comix, and Graphic Novels Review Scores Composite: $\star \star \star \star 1 / 4$}

The maximum number of stars in each category is 5 .

\section{Content:}

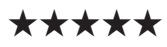

UIC offers an unparalleled package of primary, secondary, documentary, and magazine source material in the study of comic arts and the graphic novel. The current release contains 248 comic series, 1,408 comic books totalling 88,297 pages. This growth area in academic study is well served by Alexander Street's visual and scholarly approach to digital curation of this vast collection of cultural artefact.

\section{Searchability:}

While better than most, UIC's search function and options loses points for lack of advanced sorting options and for not utilizing the latest in page-turning software which would make this database a pleasure for tablet users.

\section{Pricing Options:}

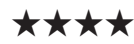

UIC is expensive compared to other graphic heavy databases; however Alexander Street does offer a sliding scale to academic institutions based on FTE and the purchaser has the option to lease the product to gauge if usage will justify purchase. Also, compared with the time and effort required to acquire the individual elements in the database UIC is the affordable choice.

\section{Contract Options:}

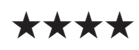

ASP offers a standard contract without egregious restrictions to authorized users. It allows Interlibrary Loan, integration in electronic learning environments, creation of course packs, and continues to add content up to the goal of 100,000 pages.

mote users through proxy server. COUNTER compliant usage data is provided by Alexander Street Press.

Owners of perpetual rights may, upon completion of the file, choose to load data onto a local server; otherwise access to UIC is in digital form stored by Alexander Street Press at one or more locations. Libraries may fulfill Interlibrary Loan requests by secure transmission only whereby the electronic file is deleted immediately after printing by the borrowing institution, and where the purpose is research or private study and not for commercial use.

\section{Author's References}

Cheryl LaGuardia, (2011) "Underground and Independent Comics, Comix, and Graphic NovelsAlexander Street Press." Library

\section{Contact Information}
Alexander Street Press
3212 Duke Street
Alexandria, VA 22314
Phone: (800) 889-5937
(703) $212-8520$
E-mail: <sales@alexanderstreet.com>
URL: <http://alexanderstreet.com>

Journal eReviews. <http://www.libraryjournal.com/lj/reviewsreference/889071283/underground_and_independent_comics.html.csp >.

Lesley S.J. Farmer, (2011) "Underground and Independent Comics, Comix, and Graphic Novels", Reference Reviews, Vol. 25 Iss: 6, pp. $52-53$

\section{Endnotes}

1. "Comics in Academia" Greg Urquhart, ASP presented at the Northeast Modern Languages Association. Feb. 28th, 2009. http://video. google.com/videoplay?docid=-5982454000795645174\#

2. For a full discussion of Wertham's attack and its influence on comic culture see, Hajdu, David. 2008. The ten-cent plague: The great comic-book scare and how it changed America. New York: Farrar, Straus and Giroux.

3. See the recently presented "Comics, Graphic Novels, Manga, and Libraries," a look at how censorship affects comics around the world, by IFLA 9 November 2011, or the necessity of the Comic Book Legal Defense Fund http://cbldf.org/.

\section{About the Author}

Mary Claire Vandenburg is a librarian at the W.D. Jordan Special Collections Library at Queen's University Library in Kingston, Ontario, where she serves as liaison to the departments of English Language and Literature, Classics, and Psychology. She is a 1997 M.L I.S. graduate of Dalhousie University. 